\title{
Eco-industrial parks: technologies and procedures for low environmental impacts
}

\author{
A. Boeri \& D. Longo \\ University of Bologna, DAPT, Faculty of Architecture of Cesena, Italy
}

\begin{abstract}
Negative environmental impacts related to the production system entail the rethinking of existing industrial areas and its organizational and technical requirements.

An eco-industrial area is a new organization of the production site that aims to facilitate companies to achieve their environmental objectives. The model of this area is based on the assumption that infrastructures and services are present in the industrial site and managed so to create business development, reducing environmental impact.

This new concept of industrial area, characterized by organizational and technical requirements aiming at minimizing the environmental impacts, arises from the need to replace the so-called end-of-pipe approach with the principle of prevention one, therefore removing, as much as possible, pollutants from the production cycle.

An ever increasing number of countries are regulating new and existing industrial areas, through specific standards that provide measures and actions taking into consideration the ecological aspects.

The production model of ecological industrial areas is based on the principle of low environmental impact, assured through planning of infrastructures, services and production cycles resulting in territory and companies' development, while preventing and controlling environmental pollution.

This paper focuses on the importance of technological innovation. In particular it aims at defining the performance of industrial areas and at contributing to the definition of specific environmental factors monitoring: the greenhouse effect, $\mathrm{CO}^{2}$ emissions, the presence of toxic elements, the consumption of non renewable resources (energy and materials), the exploitation of natural resources, the depletion of biodiversity, soil contamination, water and air pollution, as well as noise and electromagnetic pollution.
\end{abstract}


This paper highlights the critical aspects and considers the objectives to be achieved for attending the "best situation". The analysis of the critical factors of the industrial area should correspond to their ranking in terms of dimensions and of coping with their conscious choices.

Some best practices are described as reference. The aim is to propose low environmental impact industrial areas, including the transformation of existing ones, highlighting the importance of a sustainable integrated management in relation to the urban or suburban area they are in.

Keywords: innovation, technology, sustainability, environmentally friendly industry, university research.

\section{Introduction}

The definition of a productive area ecologically equipped (fig. 1) supposes the use of clean technologies for the installation and management of industrial areas [1]. A recent standard provides that in production areas specific performance-related requirements, ensuring the health and safety as well as hygiene at work, aimed at preventing and reducing air pollution, water and soil contamination, are complied with.

These requirements also concern the proper disposal and the possibility of waste recycling, as well as the treatment of wastewater, a reduction in energy consumption and its efficient use; prevention, control and management of risks of accidents; a suitable and efficient access for people and goods.

This approach presumes the application of ecological-related technologies and infrastructural solutions, foreseeing, for instance, the installation of energy production plants from alternative sources or of high efficiency plants (solar, cogeneration, micro generation) and the use of green building techniques for industrial constructions [2].

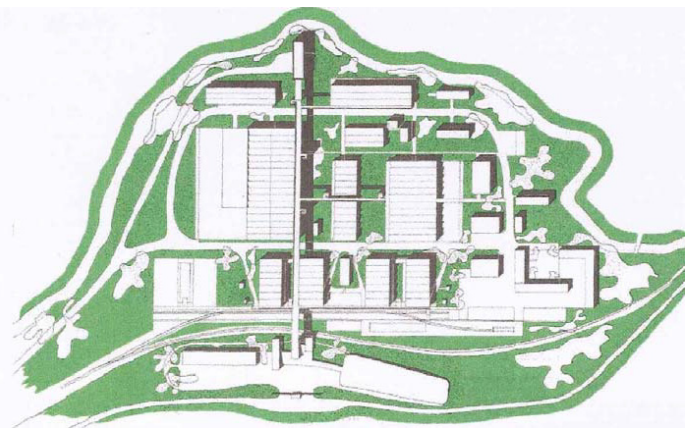

Figure 1: $\quad$ Le Corbusier - the green industry (1944).

\section{The methodological approach}

The model of eco-friendly productive area with high environmental performances should be aiming at [3]: 
- facilitating small and medium sized companies in reaching a better level of their own environmental performances, through the adoption in common of infrastructures and services of high quality they otherwise wouldn't be able to have access to or manage, individually;

- allowing the control and reduction of the combined impacts, generated by all said small and medium sized companies;

- easing a more efficient control of environmental impacts by the relevant authorities;

- facilitating the environmental certification of each single company, from technical and economical point of view, through the production area environmental management;

- facilitating or not requiring companies in obtaining the environmental licenses both for issue or renewal purposes;

- simplifying all procedures related to the set up and establishment of companies in the production area;

- applying the principles of precaution, prevention and reduction of pollution;

- involving the companies in the process of an ongoing improvement of the environmental performances in the production area and in a process related to environmental responsibility.

The environmental performances of eco-industrial parks are monitored by the Management Authority which is also responsible for coordinating the implementation of an area-related environmental plan to the common benefit of all companies. The Management could have the power to undersign collective agreements (e.g. energy supply contracts), promote the area under an economic and environmental point of view, to implement waste recycling, wastewater treatment, manage the lighting networks, issue the environmental licenses related to the services it provides for the common use of all companies. The advantages for a company deciding to establish itself in the productive area such as this are tied to the use of common infrastructures and their related management and to the services provided.

The development of industrial areas of high environmental energy quality level can improve the general competitiveness of the production system, offering costs savings, infrastructures and services in common, a shared environmental management and a costs reduction for the energy supply [4].

\section{Definition of eco-industrial park performance related profile}

The new industrial areas which are developing in some Italian regions have been designed to assure specific energy and environmental requirements, therefore planed so to integrate R\&D and facilitate companies. This approach involves high investments costs and presents higher problems for the regional, district and area authorities during negotiation with private companies [5].

The area attractiveness can be increased by improving its overall image through a revision of the urban planning, the quality of its architecture, a presetting of mitigation works and of natural setting, highlighting the ecological quality of the area, while offering information and support to companies for the 
access to European funds - even for the different environmental certifications and promoting and developing all necessary territorial marketing initiatives in order to facilitate the transfer of companies reputed leaders in the own field, today delocalised.

As regards the performance related characteristics, one of the most interesting and comprehensive reference is the legislation on the matter of technical coordination and guide-lines concerning the realization of eco-friendly industrial areas in Emilia Romagna, as provided by the Regional Law.

The objective of this instrument is to define the modalities for the realization and the management of eco-industrial parks in the region and for a whither and increasing establishment of productive areas equipped with technical and organizational requirements, aiming at limiting and managing the impact on the environment to prevent pollution as well as support a sustainable production and economical development.

To this purpose, the choices to be adopted as regards the systems present in the area are as follow: the economical system, the set up, infrastructures and transport system, water supply, hydro-geological safety, landscaping, energy supply, waste management.

For each of the above, the activities aiming at ensuring environmental, economical and social sustainability are as follows [6].

\section{Economic and establishment system}

Provide the establishment of activities granting environmental, social and economical sustainability.

The ecosystem approach to be adopted in the definition of the characteristics of eco-industrial parks refers to planning, within the scope of which decisions of primary importance have to be taken, such as for instance the location of the plant, the buildings ratio index, the use allowed, the applicable technologies related to environmental quality, to a responsible production and consumption, to a high quality level of the work place, to the end of the resources natural cycles.

The objective is to ensure /assure wellbeing and comfort for the end-users, high performances of buildings in terms of energy saving, integration of the buildings within their specific environment.

\section{Infrastructure and transport system}

Increase the efficiency of road and rail networks, of the exchange centres and of the logistic platforms to optimize the access to the area.

Eco-industrial park infrastructure system has to foresee optimal access for goods and people through the local public transport system, the area mobility management and opportunities of a more structured flow of goods moved by the logistic systems.

An efficient access road system has to be matched by a good internal organization of the production area, which will ensure a suitable environmental 
management, thanks to also the use of proper signs and an improved service and promotion of the local public transport.

The road set up allows a rationalization of logistics, with subsequent costs reduction for the companies and a decrease of vehicles in circulation contributes to limit in emissions.

The role of a Mobility Manager should be taken into consideration, responsible for the company mobility to optimize the home-work transfer of the employees; this role could be covered also by the Management Authority in order to identify activities that benefit the SME.

The Mobility Manager should plan and evaluate the goods transport system in the area and coordinate the logistic network.

\section{Water supply and hydro-geological safety}

In the eco-industrial park area over-ground and underground water systems should be controlled and improved to protect water supplies (fig. 2), reduce consumption and waste; at the same time the soil fertility has to be protected, avoiding any erosion and contamination processes, caused by specific activities carried out or by accident spillages.

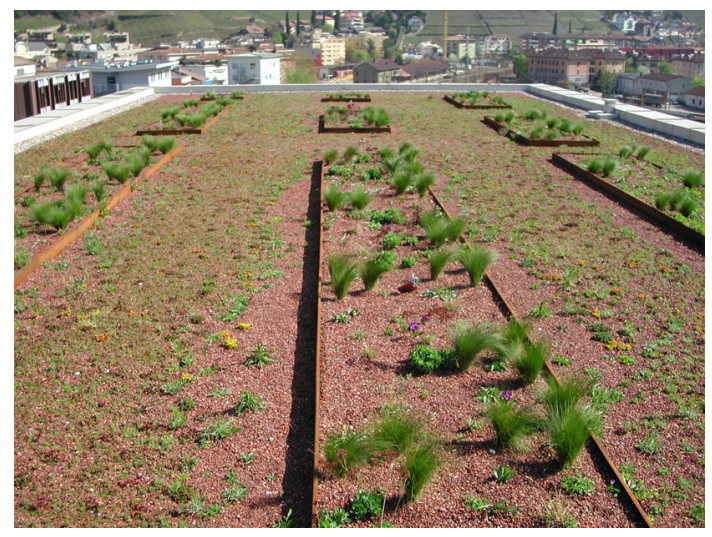

Figure 2: Integrated application of technologies for management and collection of rainwater. Calculation of the coefficient of runoff of water and the achievement of minimum standards of permeability that could be required for each industrial building.

\section{Landscaping system}

Improve the quality of open spaces.

The objectives to be achieved during the planning of an eco-industrial park include a guarantee quality of the open spaces (fig. 3). 


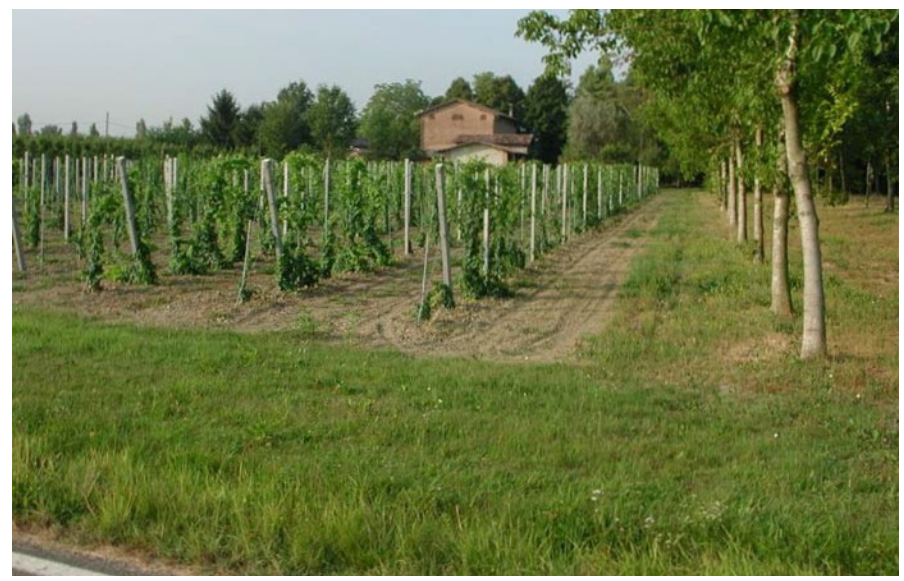

Figure 3: A green area to be preserved by the plan of a future eco-industrial park.

It is possible when the intervention results in harmony with the natural and anthropic elements of the landscape it is set in.

The eco-industrial park urban landscaping plan should take into consideration the pre-existing elements to be promoted and/or reused. Among these, one of the most important elements is any water courses present because they are considered very important ecological corridors as they are used as a crossing route by the local flora and fauna.

Improve the quality of the existing and new buildings.

Besides the quality of open spaces, but not secondary to it, the quality of buildings is another objective to be achieved, through the experimentation and application of new materials and design solutions, as well as the development of innovative methods for diagnosis and monitoring of energy consumption and overall performances.

\section{Energy supply system}

Reduce consumption of energy for thermal-humidity indoor control.

Energy consumption must be reduced by at least $20 \%$ when compared to the current one, according to the international agreements on climate changes.

A minimum standard of energy efficiency class should be provided through incentives aiming at reducing planning application fees together with the requirement of using solar panels (fig. 4).

\section{Waste management system}

Waste management plays a significant role in developing a sustainable environmental strategy. The models of integrated waste management aim at not only preventing and reducing the environmental impact of the management 


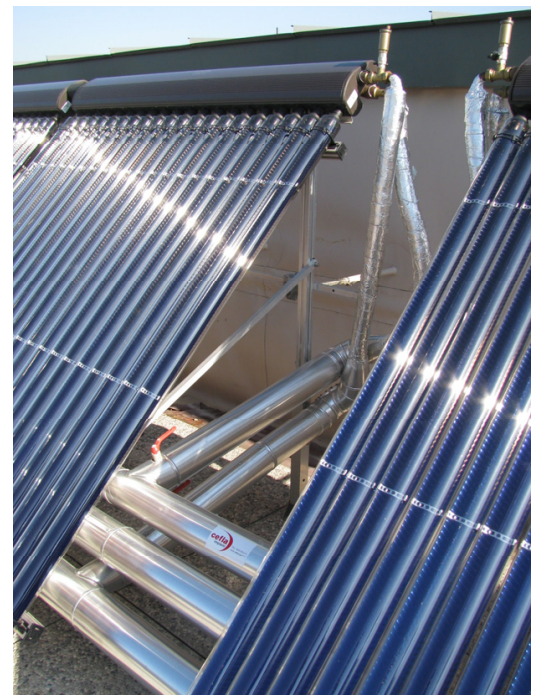

Figure 4: $\quad$ Solar panels on an industrial building roof.

cycle, but also at the overall improvement of the "man-environment" system and at a more sustainable use of resources. In general the industrial sector should be paying more attention to the technologies for reducing and recovery/recycling waste in the relevant manufacturing processes, prompted and encouraged by technical and economic requirements and by an in depth knowledge of their production cycles.

\section{A case study: the Nonantola (MO) eco-industrial park, a detailed plan - PIP production area "Gazzate"}

\subsection{Location and characteristics of the area}

The area is located to the west of the town of Nonantola, near an existing production area, known as "Gazzate" (fig. 5), representing the area natural and consequent expansion to the north.

The existing production area covers about 550.000 square meters.

The total land area of the project (ST) is of $171.612 \mathrm{~m}^{2}$. Here it's possible to built max $61.530 \mathrm{~m}^{2}$ of floor area for productive use.

A preliminary study has identified the main issues and has defined possible action-lines for improving and streamlining the agglomeration.

In particular, a feasibility study was prepared by the Agency for Energy and Sustainable Development of Modena in order to achieve energy saving in energy production and distribution facilities.

The planned expansion will be carried out under the guidance of a single responsible body, the Consortium for Productive Activities Areas and Services, which shall be responsible for planning, Plan implementation and for managing 


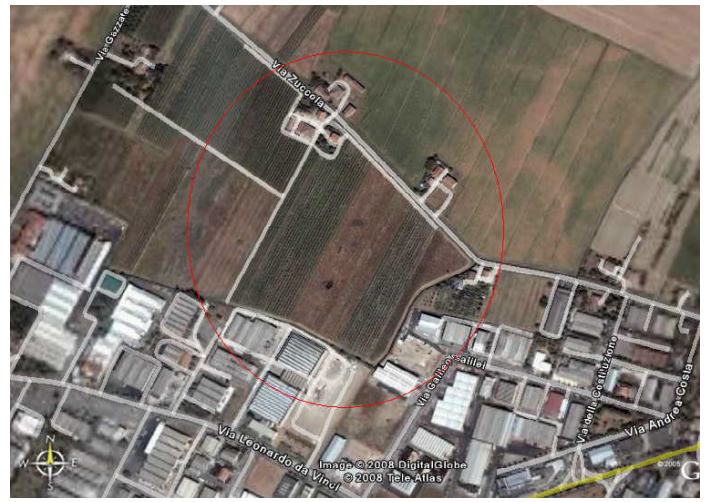

Figure 5: $\quad$ Satellite image of the area of Gazzate.

the industrial area, paying particular attention to the environmental compatibility aspects.

\subsection{Social-economical and establishment system}

Common spaces and services.

Within the area $1.200 \mathrm{~m}^{2}$ are designated for services for industries and the site personnel.

This forecast is closely linked to the requirement on the matter of environmental and social aspects, laid out in the so-called draft agreement.

In the area there is cars only parking place, a parking lot for heavy vehicles, a building for community services and a co-generation plant. A small park surrounds the area to the south.

\subsection{Sewers and water purification systems}

Systems for reducing water runoff and for ensuring the quality of surface water. The management of storm water run-off is also provided through the collection and treatment of rainwater and, where possible, its partial reuse.

Systems for ensuring the disposal of waste water and for providing water purification systems. Separate networks for collection systems of rain water and sewage are provided and particular attention is paid to ensuring a suitable treatment plant.

\subsection{Water supply system}

Systems for reusing of rainwater.

Realization of public and privately owned irrigation systems fed by rain water basins in order to avoid or limit the number of connections to the public water system.

Adoption of systems to optimize the water cycle:

- installation of solar plants for the production of hot water: $128 \mathrm{~m}^{2}$ of solar collectors are forecasted; 
- a reduction of water runoff peaks through the implementation of green roofs on top of the industrial buildings; use of water saving bathroom fittings;

- limiting of soil sealing ensuring a significant green area both public and privately owned lots;

- collection of rainwater in the productive area in order to purify it rather than leaving it to seep into the ground;

- assessment of water needs of the area and inspection of the area for the water presence.

\subsection{Energy supply system}

Reduction of energy consumption for the thermo-hygro indoor control:

- thermal insulation of the buildings envelopes compliant with the energy parameters set by law (LD 311/2006 and subsequent amendments and supplements);

- adoption of shielding systems for the glazed surfaces, suitably positioned and sized to avoid glare and overheating in the summer;

- natural ventilation systems or in combination with passive solar systems to ensure air circulation inside; this is important for improving the levels of indoor comfort;

- district heating network fed by high-efficiency cogeneration system;

- heating system by using floor radiant panels (fig. 6);

- heat pumps instead of traditional boilers are particularly suitable for emitting heat at low temperatures in combination with under floor heating system;

- the exposure was planned to provide the maximum intake of natural light and maximize passive solar energy;

- the distance between buildings is such to ensure each building the right sunlight intake and with no shadows, projected from the surrounding buildings, as checked by 21 st December;

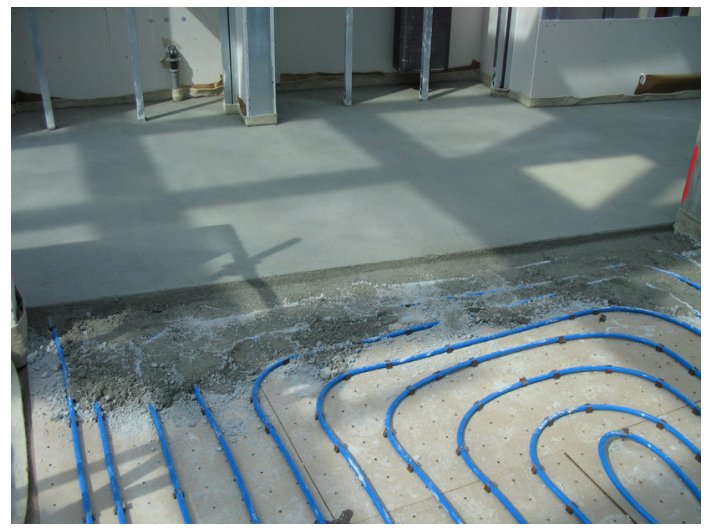

Figure 6: Radiant panels for heating system. 
- the glazed surfaces are sized in relation to the orientation and to the needs of sunlight;

- the production areas inside the buildings receive light through shed openings located on the roofs and installed with a 30 degrees slope and suitably spaced to avoid shading; this system enables the installation of solar/photovoltaic panels on the south side (fig. 7).

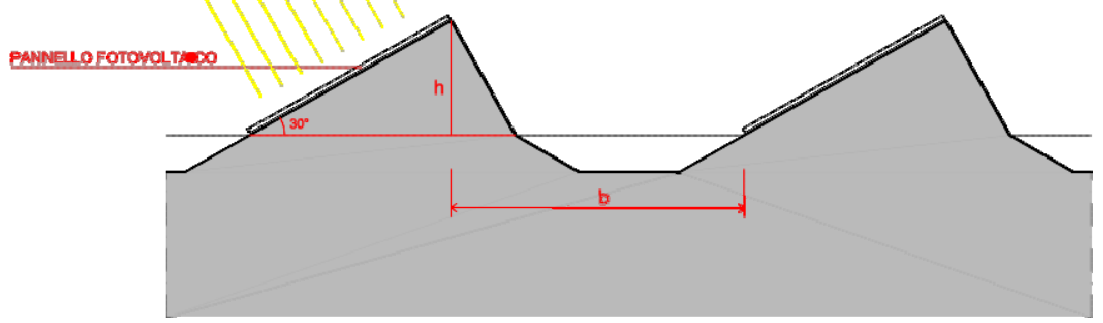

Figure 7: Photovoltaic panels on shed roofs.

Area common energy management.

In the industrial area a particularly efficient energy management is possible since all companies can be supplied by a single district heating system powered by high efficiency cogeneration plant.

The district heating network (fig. 8) enables to centralize the thermal energy production and therefore to better control the emissions and efficiency of the plant/s connected to the network.

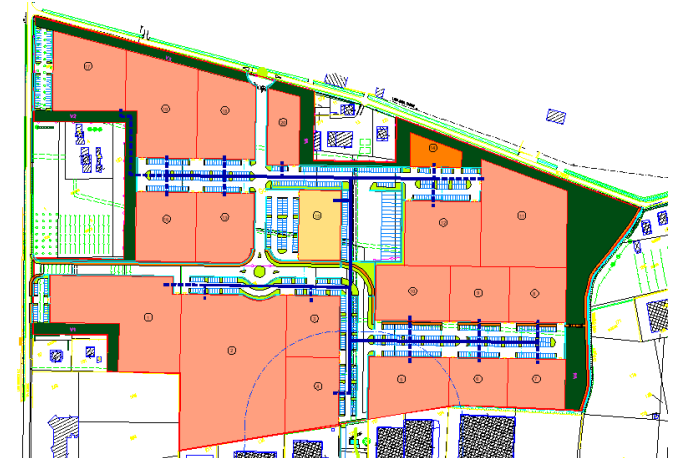

Figure 8: The eco-industrial area of Gazzate. Proposal for district heating network. 


\subsection{Infrastructures and logistics}

The objective of the program developed by the Institute for Transport and Logistics of the Emilia Romagna Region with the Consortium and other major companies of Modena is the reduction of mobility and optimization of the logistics of the companies already established or to be established in the area.

Through a planning of the movement of goods and people significant advantages can be obtained in terms of efficiency, traffic relief, a reduction of energy consumptions, costs savings and environmental benefits (fig. 9).

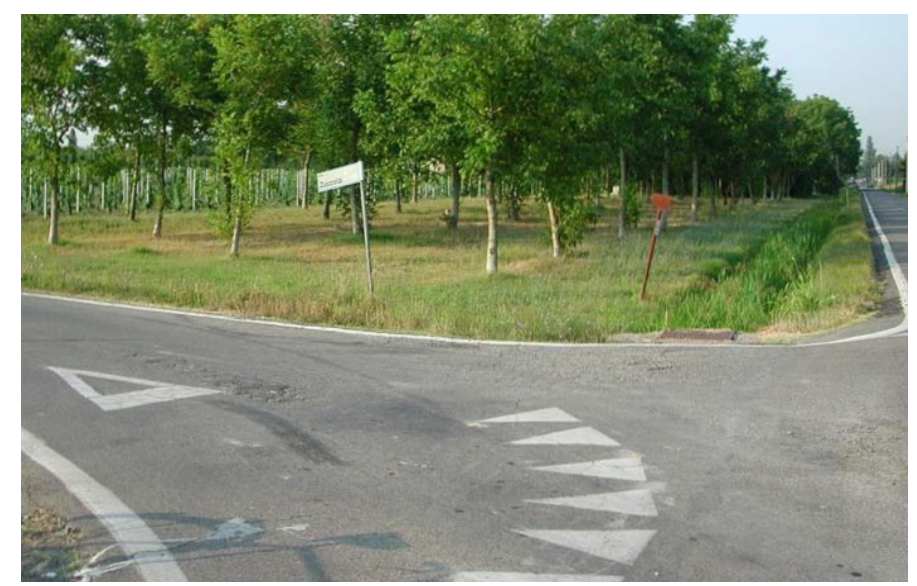

Figure 9: The reduction of mobility in the area could lead a reduction of energy consumption and decrease in traffic.

To this end, the work plan developed involves the testing of a model for transport sharing between the companies.

\subsection{Landscaping system}

Quality of open spaces.

The project aims at minimizing the impact of the intervention on the landscape through the establishment of suitable green area.

Improve the quality of the existing and new buildings.

The goal of achieving high standards of urban and ecological-environmental quality leads, first of all, to the decision of adopting the relevant current Standards.

The method adopted strives to combine different aspects: economical, social and environmental ones, with a view to create a "workplace", where the production function is positively influenced by a series of factors that determine, at the same time, its environmental compatibility. 
188 Sustainable Development and Planning V

\section{References}

[1] Gibbs David, Deutz Pauline, Implementing industrial ecology. Planning for eco-industrial parks in the USA, Geoforum 36, pp. 452-464, 2005

[2] Cavallo Marino, Stacchini Valeria (edited by), La qualificazione degli insediamenti industriali. Verso la costruzione di Aree Produttive Ecologicamente Attrezzate, CLUEB, 2007

[3] Bollini Gabriele, Borsari Luca, Stacchini Valeria (edited by), Insediamenti Industriali e Sostenibilità. Linee guida per la realizzazione delle Aree Produttive Ecologicamente Attrezzate della Provincia di Bologna, Alinea Editrice, 2007

[4] Tarantini Mario, Dominici Arianna, Analisi dei parchi eco-industriali europei, ENEA, PROTP135-090, 2005

[5] D’Angelo Emidio, Manna Carlo, Marani Mauro (edited by), Energia e ambiente. Enea per le regioni e i distretti produttivi, Dossier Workshop Roma. 5 luglio 2006

[6] Boeri Andrea, Longo Danila, Criteria and technologies for ecological industrial areas. Collaboration between industry and University, in INTED 2010 - Proceedings of International Technology, Education and Development Conference, Valencia, march 2010, IATED, pp. 2238-2248 